\title{
Contribuições dos arquétipos para a construção de projetos de design transmídia
}

\author{
Contributions of archetypes for building design projects transmedia \\ - André Luiz Sens \\ UFSC, Brasil \\ andrelsens@gmal.com \\ - Felipe Machado de Souza \\ PUCPR, Brasil \\ mazafelipe@gmail.com
}

\begin{abstract}
The mass presence of devices and interactive and collaborative environments, driven by advances in information and communication technology, intensified experiences ever more sophisticated consumption. In this context it arises transmidiação, which deals with the construction of an articulated narrative universe across multiple media platforms for experiential deepening the viewer. Seeking a methodological tool that can assist in the development of transmedia design projects this paper investigates, through exploratory research and case study, the possible contributions of archetypes to create design more efficient and immersive.
\end{abstract}

Keywords: Design, Transmedia, Archetypes

\section{Introdução}

A presença massificada de dispositivos e ambientes interativos e colaborativos, impulsionada pelos avanços da tecnologia da comunicação e informação, intensificaram experiências cada vez mais sofisticadas de consumo. A televisão, o jornal e outros veículos tradicionais receberam novas funções, suportes e papeis sociais, coexistindo com "novas mídias" que estimulam a imersão e a participação dos agentes envolvidos na produção e uso de conteúdos, marcas e serviços.

Henry Jenkis (2009), fundamentado nos conceitos de convergência midiática, inteligência coletiva e cultura participativa, analisa o fluxo de conteúdos que perpassa entre múltiplos suportes e mercados midiáticos, considerando o consumidor, seu comportamento migratório entre canais e sua participação ativa em busca de novas formas de entretenimento, informação e conhecimento. Dentre os fenômenos que emergem desta condição socio-cultural está a transmidiação, que trata da construção de um universo narrativo articulado entre múltiplas plataformas midiáticas para um aprofundamento experiencial do espectador.

Apesar dos estudos sobre transmidiação concentraremse principalmente nas áreas da publicidade e jornalismo, é possível notar aproximações científicas cada vez maiores com o design, principalmente na investigação sobre os desafios em articular estruturas estéticas e simbólicas complexas a fim de gerar soluções comunicacionais e industriais. Dena (2009), por exemplo, defende a ideia de que a transmidiação se desenvolve em uma "ecologia de design", enquanto Lupton e Phillips (2008) descrevem o design como um empreendimento transmídia.

Entretanto, os autores não apresentam de modo geral as motivações cognitivas e emocionais que levam esses espectadores e produtores a se engajarem na imersão e construção desses universos narrativos. O cognitivista Norman (2010) sugere que esse processo de engajamento envolve motivações, tanto relacionadas com a exploração multissensorial do prazer e da diversão, como também ao estímulo a participação colaborativa. Contudo não desenvolve argumentos indicativos claros de como essa cognição é ativada com o intuito de favorecer os tipos de experiência e consumo defendidos por Jenkis (2006).

Dentre as correntes que buscam entender a psique humana, Jung (2008a) apresenta os arquétipos como uma forma de fundamentar o entendimento do funcionamento dessas experiências que se manifestam a partir de contextos simbólicos e narrativos. A partir dos arquétipos, é possível identificar possíveis diretrizes que possam orientar o desenvolvimento de projetos transmidiáticos mais eficientes, envolventes e inovadores. Isso se deve justamente pela caracterização dos arquétipos como padrões basais de organizações psíquicas encontrados em todos os indivíduos, independente das referências culturais e geográficas (MORAES, 2010). Isto é, falar em arquétipo significa reconhecer uma predisposição a determinados comportamentos, assim como a predisposição a 
aprendizagem. Nesse sentido, os arquétipos podem ser um meio pelo qual o consumidor pode dizer aos outros - ou a si próprio - o tipo de pessoa que é ou que gostaria de ser e a tribo a qual pertence. Passaram a servir como dispositivos simbólicos que permitem aos consumidores projetar seu eu e sua auto-imagem (KELLER e MACHADO, 2007).

$\mathrm{Na}$ indústria do entretenimento, costuma-se explorar justamente esses arquétipos, através de personagens, cenários e histórias nas diversas mídias, de modo a ativar e mobilizar qualquer indivíduo por inteiro, modificando a forma como ele, e os outros, percebem ou reagem à realidade. Identificar esses comportamentos pode ser uma ferramenta metodológica importante na busca do desenvolvimento de projetos narrativos mais imersivos, sobretudo aqueles tratados no contexto transmidiático, que envolvem a construção de universos multimodais e a ativa participação e engajamento dos atores envolvidos.

Este artigo visa identificar a partir de uma pesquisa exploratória, as possíveis contribuições dos arquétipos para a criação de projetos de design transmidiáticos eficientes em termos mercadológicos, experienciais e educacionais.

\section{Abordagem Metodológica}

Como método de pesquisa foi selecionada a pesquisa exploratória que segundo Gil (2002).

"Tem como objetivo proporcionar maior familiaridade com o problema, com vistas a torná-lo mais explícito ou a construir hipóteses. Pode-se dizer que estas pesquisas têm como objetivo principal o aprimoramento de ideias ou a descoberta de intuições." (GIL, 2002)

Segundo o autor este tipo de pesquisa envolve levantamento bibliográfico, entrevistas com pessoas que tenham experiência prática com o tema e a análise de exemplos que facilitem a compreensão do problema. É uma abordagem livre, mas que na maioria dos casos é desenvolvida com uma pesquisa bibliográfica ou estudo de caso.

Neste artigo a pesquisa exploratória será conduzida como uma pesquisa bibliográfica sobre diretrizes para projetos de design transmídia e o uso de arquétipos na construção de marcas e na publicidade, buscando estabelecer uma relação entre os temas. O estudo de caso sobre um projeto transmidiático complementa a pesquisa.

\section{Design transmídia: projetando universos imersivos e colaborativos}

Jenkis (2006) descreve as narrativas transmidiáticas (transmedia storytelling) como um dos principais fenômenos dessa cultura da convergência. Descreve como as histórias são construídas e estruturadas através de múltiplos canais midiáticos para a construção de um mundo narrativo. Filmes, jogos, livros, programas de tevê e outros produtos midiáticos são interligados a fim de produzir experiências imersivas de consumo, interação e participação. Nesse sentido, são explorados os potenciais comunicacionais de cada um dos meios de forma a estimular o engajamento dos consumidores na conexão com as partes e extensões da mesma história e também na produção de novos conteúdos para a ampliação desse universo narrativo.

A trilogia Matrix, dos irmãos Wachowski, costuma ser citada por Jenkins (2009) e outros autores como um exemplo bem sucedido de um projeto transmídia. Os filmes forneciam pistas e questionamentos que instigaram discussões entre os fãs em fóruns e redes sociais. Além disso, alguns elementos da história, muitas vezes secundários à trama, foram explorados de modo expandido através de outros textos e abordagens estéticas em quadrinhos, animes e games, lançados antes, após ou concomitantemente às películas:

"No curta de animação Final Flight of the Osiris (2003), a protagonista, Jue, sacrifica a própria vida para entregar uma mensagem à tripulação do Nabucodonosor. A carta contém informações sobre as máquinas que abrem caminho em direção a Zion. Nos momentos finais do anime, Jue joga a carta numa caixa de correio. Na abertura do game Enter the Matrix, a primeira missão do jogador é resgatar a carta do correio e levá-la a nossos heróis. E as cenas de abertura de Matrix Reloaded mostram os personagens discutindo a "última missão de Osíris" (JENKINS, 2009).

O conceito de franquia transmídia emerge ao posicionar essa prática multiplataforma em uma ecologia comercial. As franquias costumam ser apresentadas de formas variadas nas práticas e leis que regem a indústria e o comércio. Porém, de acordo com Johnson (2009), o nicho do entretenimento costuma definir as franquias transmidiáticas como propriedades intelectuais que atuam no uso e gestão de um mundo imaginário em diferentes mídias, por meio de produtos, estruturas criativas e nós de distribuição, a fim de gerar receitas adicionais. A exploração comercial e multiplataforma das personagens Mickey Mouse e Felix the Cat a partir da década de 1920 (THOMPSON, 2007) podem ser tomados como exemplos primordiais desse modelo de negócio de franquias transmídia, mesmo antes do surgimento do termo. Outro caso significativo é a saga de Star Wars. Em 1976, iniciou um projeto de transmidiação a partir dos filmes que culminou em uma franquia global que produz e promove todos o produtos midiáticos relacionados: camisetas, aplicativos, action figures, filmes, programas de TV, livros, sites, quadrinhos, brinquedos, games e outros (GIOVAGNOLI, 2011).

Entretanto, a expansão e articulação desses universos consideram não só as plataformas, como também um público-alvo específico: os fãs (JENKIS, 2009). Em geral, esses indivíduos apaixonados pelo mundo narrativo costumam participar ativamente na avaliação ou construção de novos textos, seja através da interação lúdica, do diálogo, na resolução de problemas ou no desempenho de papeis dentro da narrativa (RYAN, 2004). Em alguns casos, tornam-se verdadeiros prossumidores (TOFFLER, 1980), ou seja, além de consumirem, são responsáveis pela produção de conteúdos relacionados a história.

Apesar da complexidade desses projetos, existem estudos 
que visam entender as estruturas desenvolvidas nesses mundos com finalidades práticas, tanto mercadológicas e educativas. Nesse sentido, Von Stackelberg (2011) e Ciancia (2015) apresentam frameworks de design que buscam resolver as especificidades desses projetos transmidiáticos. Tratam de relacionar os diversos elementos que compõem uma narrativa com aspectos relacionados ao engajamento dos usuários e ao design interação.

Os esforços dessas pesquisas, entretanto, concentram-se em oferecer um método estruturado para o trabalho de designers e desenvolvedores. Contudo não aprofundam sobre a capacidade de envolvimento desse público de fãs prossumidores, capazes de investir tempo, energia e dinheiro na participação ativa e na expansão dessas narrativas. Neste contexto, as estruturas arquetípicas podem oferecer respostas para um entendimento mais preciso sobre a eficiência dessas histórias, justamente por explorarem aspectos simbólicos fundamentados em comportamentos psicológicos comuns aos seres humanos.

\section{Narrativas, pensamento não linear e arquétipos}

Para compreender as contribuições que os arquétipos podem trazer para o design das narrativas transmidiáticas é preciso compreender, primeiro, a importância da narrativa para o contexto humano. Para Jung (2008a) as estruturas narrativas são formas de expressões dos arquétipos, isto é, os fatos da mente manifestos em uma ficção sobre o assunto. De acordo com o fundador da psicologia analítica, as narrativas possuem dimensões simbólicas de representações e projeções que ensinam sobre condições inerentemente humanas. Embora Jung tenha direcionado seus estudos para os mitos e os contos, essa modalidade de discurso e composição de atos em uma história, hoje, segundo Bruner (1997, apud VIEIRA, 2003, p. 30) é denominada como narrativa. Dessa maneira, todas as formas de narrativa, como os mitos e os contos, tem como base realidades arquetípicas, aos quais todos os seres humanos podem se deparar ao longo de suas vidas. Segundo Vieira (2003, p. 30) "a representação de nossa experiência de vida é, portanto, uma narrativa, e nós utilizamos a narrativa como uma ferramenta, a fim de organizar nosso contato com o mundo em termos de experiência inteligível".

Ao abordar as manifestações por meio das realidades arquetípicas - como os mitos, os contos e as narrativas de modo geral - muitas vezes, tem-se a noção equivocada de discorrer sobre um tempo remoto, mitológico, distante da atualidade. Muito provavelmente, tal equívoco se dá, segundo Jung (2008b), porque na atual cientificidade tende-se a enfatizar mais o pensamento linear ou lógico ${ }^{1}$, devido a incessante busca pela realidade material. Com isso, desconsidera-se que existe outra forma de pensar, a não linear. Essa outra forma, que é acessada nas narrativas transmídias, rege o mundo

1 Pode-se definir como o pensamento baseado em linguagem e conceito linguístico. Tem como única finalidade a comunicação, é trabalhoso, linear, lógico e cansativo. Fenômeno inteiramente consciente que imita a realidade e procura agir sobre ela (JUNG, 2008b). imaginário, sendo esse alimentado pelas fantasias e sonhos ${ }^{2}$. E, justamente, no pensamento não linear, que Jung acreditava ocorrer a construção dos mitos e, portanto, das narrativas (VIEIRA, 2003).

Embora na contemporaneidade não se perceba sua intensidade, há quem acredite que o pensamento não lógico o mesmo que os povos primitivos utilizavam para a explicação do surgimento do universo - foi renegado. Na verdade, ocorre exatamente o contrário, eles atuam de forma potencializada justamente porque adquiriram aspectos mais inconscientes. Além disso, é possível observá-los, preponderante, no mundo lúdico das crianças.

Jung (2008b) compara o pensamento das crianças ao espírito antigo, pois como na mitologia grega elas também animam as coisas, ou seja, atribuem personalidade e adaptam esteticamente o mundo real as fantasias e esperanças subjetivas.

"Infelizmente recebemos na escola uma ideia muito precária da riqueza e da enorme expressividade da mitologia grega. Toda esta força criadora que o homem moderno aplica na ciência e na técnica, o antigo dedicou à sua mitologia.[...] Esta atividade do espírito antigo agia de modo essencialmente artístico. $O$ alvo do interesse não parece ter sido compreender o "como o mundo real com a maior objetividade e exatidão possíveis, e sim adaptálo esteticamente a fantasias e esperanças subjetivas.[...] E cada coisa tinha seu demônio, isto é, era animada e igual ao homem ou seu irmão, o animal. Até o disco solar recebia asas ou pés para ilustrar o seu movimento, mas inteiramente ligada às fantasias subjetivas. Não será preciso provar que a criança pensa de modo semelhante ela anima suas bonecas e brinquedos e, em crianças dotadas de imaginação, vemos facilmente que vivem num mundo mágico" (JUNG, 2008b, p. 17).

Se ainda predominam as fantasias no mundo infantil, significa que a psique, no decorrer da evolução, trouxe vestígios nítidos do pensamento não linear na subjetividade do homem contemporâneo; mesmo que este não perceba a força de sua atuação. Para Jung (2008a) as 80 gerações que se passaram desde a época áurea da cultura grega não fizeram desaparecer totalmente da alma humana os hábitos e convicções deste povo tão desenvolvido.

Reconhece-se que o pensamento fantasia, ainda que menos explícito na sociedade atual, é, todavia, indispensável para a construção da humanidade e do indivíduo. Isso acontece porque essa forma de pensar está arraigada no espírito universal criador de uma cultura. Assim, depois de compreendida a necessidade psíquica de conservar as narrativas em um mundo fantasioso e imaginário para a civilização moderna, questiona-se, segundo Jung (2008a, p.

2 É a forma de pensamento que trabalha sem esforços, por assim dizer espontaneamente, com conteúdos encontrados prontos. Embora grande parte de seus conteúdos ainda está na área consciente, há direcionamento por motivos inconscientes que só podem ser desvendados indiretamente. Afasta-se da realidade, liberta tendências subjetivas e é improdutivo com relação a adaptação. São os sonhos, acordados ou não, e as fantasias (JUNG, 2008b). 
21), "se os homens alguma vez se libertaram totalmente dos mitos?" Considerando a narrativa uma realidade arquetípica é possível afirmar que a resposta é não.

Basta analisar os homens modernos. Embora longe de utilizarem as mesmas histórias mitológicas da antiguidade - repleta de deuses, dragões, monstros, demônios, heróis, planetas, etc. -, eles têm um arsenal de narrativas em que acorrentam suas fantasias e sonhos. Anunciantes, por exemplo, vendem produtos mitologizando-os, envolvendo-os em fantasias e ficções:

[A] publicidade funciona como uma forma romanceada de comunicação, uma ficção narrativa que usa personagens, lugares e situações fictícios, e assim por diante, a fim de envolver e interessar o consumidor, comunicar os atributos e benefícios da marca (físicos e emocionais), e posicionar perceptualmente a marca na mente do consumidor. A publicidade nos garante acesso à mente do consumidor, onde podemos criar mundos e personagens míticos, atraentes. Todas as imagens, todos os símbolos, sentimentos e associações criados e transmitidos pela publicidade se tornam partes do inventário perceptual da marca. Todo anúncio e todo comercial deveriam ser pensados como uma mitologia publicitária individual e deveriam ser cuidadosamente considerados, porque em última análise afetam a mitologia global, a imagem e a personalidade da marca (RANDAZZO, 1997, p. 31).

Desse modo, marcas, produtos e serviços usufruem dos canais de comunicação, para espalhar mitologias culturais, valores e sensibilidades que moldam comportamentos e culturas. Ao considerar a indústria de entretenimento, essa relação fica ainda mais próxima e evidente. Afinal, seus produtos midiáticos são fundamentalmente baseados em narrativas: filmes, games, novelas, livros, desenhos, etc. No intuito de contribuir para a formação da consciência pessoal e coletiva desses espectadores, jogadores ou usuários, os arquétipos aparecem nos enredos, nos personagens, nos cenários e nas histórias contadas por esses produtos.

Segundo Zoja (1992) os meios de comunicação apostam no potencial interesse do público pelos temas arquetípicos para atrair sua atenção. Petry e Silva (2004) observam ainda que os símbolos arquetípicos levam ao consumidor uma mensagem que parece familiar e remete-se ao inconsciente resultando em maior aceitação.

Filmes, jogos, programas, publicidade e demais produtos midiáticos e comunicacionais que trabalham com identidades arquetípicas tem maior possibilidade de penetrar no inconsciente coletivo e atingir de imediato as motivações dos indivíduos. Todos os indivíduos em todas as partes tem uma organização psíquica semelhante porque "os arquétipos acessam o mesmo conteúdo emocional em indivíduos de diferentes culturas ou diferentes lugares do mundo" (MORAES, 2010). Conforme Fabrício Moraes (2010) explica, os arquétipos são os padrões basais de organizações psíquicas que ordenam todo o psiquismo. Os arquétipos, portanto:

Correspondem a padrões inatos de comportamento, herdados comum à humanidade. Os arquétipos são formas sem conteúdo, correspondendo a possibilidades latentes de manifestação. São análogos aos instintos - elementos autônomos da psique inconsciente (JUNG, 2000).

Por meio de um movimento compatível com a dinâmica própria do arquétipo é possível ativá-lo ou ativar sua representação na esfera pessoal, sendo que essa pode se manifestar como imagem e, simultaneamente, emoção (FERNANDES; FIALHO, 2014). Deste modo, falar em arquétipo significa reconhecer que existem tendências inatas a determinadoscomportamentoseexperiênciasquerepresentam as grandes forças ou impulsos da alma humana como, por exemplo, a vontade de domínio, a coragem ou heroísmo, o amor, o ódio, a fé etc. (COELHO, 2003). Sendo assim, é compreensível que o uso de arquétipos na construção midiática da industria do entretenimento permita envolver o consumidor com maior interação e participação cognitiva e emocional.

Um produto com identidade arquetípica fala diretamente à matriz psíquica profunda dentro do consumidor, ativando um senso de reconhecimento e significado [...]. As imagens arquetípicas sugerem a realização dos mais básicos desejos e motivações humanos, liberando emoções e anseios profundos. [...] Os arquétipos fazem a intermediação entre produtos e a motivação do consumidor porque oferecem uma experiência intangível do significado (PEARSON; MARK, 2001, p.31).

Compreendendo a importância das narrativas, do pensamento não linear e dos arquétipos no processo psíquico e evolutivo dos seres humanos, entende-se porque a transmídiação tornou-se, hoje, relevante para as marcas atingirem, por meio das múltiplas plataformas midiáticas, seus consumidores. Pois assim, fazem com que a construção de um universo narrativo articulado garanta profunda motivação e experiência do espectador que, quando envolvido pela fantasia, não faz separação entre o real e o imaginário. Logo, as narrativas transmidiáticas tem dado novos significados para a relação - principalmente a emocional - com os indivíduos. Diferente da publicidade, que apenas orquestra arquétipos em narrativas passivas e distantes do consumidor, construindo um ideal de personagens, mundos, cenários etc., os projetos de design transmídia tem permitido novos canais de contato, possibilitando uma imersão ativa e real da exploração multissensorial, garantindo assim, a cooparticipação do prossumidor na narrativa e tudo que a engloba. Dessa forma, o envolvimento psíquico é mais profundo porque relaciona tanto o pensamento lógico quanto, principalmente, o pensamento fantasia, que ativa e estimula os arquétipos (emoções e sentimentos) de modo mais eficaz. Poderia-se dizer que os prossumidores introjetam a narrativa e somam-na a sua própria experiência de vida, confundindo os limites entre o real e virtual.

\section{Projeto Defiance}

Lançado em 2013 nos Estados Unidos com a tagline promocional "Watch the show, play the game, change the world" ("Assista o programa, jogue o jogo e mude o mundo"), Defiance é um ambicioso projeto transmídia de ficção 
científica. Envolve uma série de televisão, desenvolvida pela Universal Cable Productions e transmitida pelo canal Syfy, e um jogo MMORPG (Massively Multiplayer Online Role Playing Game) conjuntamente produzido e lançado em colaboração com a Trion Worlds e disponível para os dispositivos Xbox 360, PS3 e PC.

A trama, articulada entre ambas as mídias, acontece em 2046, em uma Terra radicalmente transformada, com novas espécies de animais e vegetais, oriundas do espaço ou surgidas pela contaminação com os seres nativos. Joshua Nolan, o Guardião da Lei da cidade, e sua filha adotiva Irisa, da raça Irathiet, são as personagens protagonistas da série. Eles vivem em Defiance, uma comunidade localizada na região St. Louis no estado de Missouri, onde os seres humanos e raças extraterrestres - os Votans - vivem juntos.

Diferente da série, o jogo acontece em outra região, na baía de São Francisco nos EUA. Nele, é possível jogar como um humano ou um alienígena. As definições físicas dessas personagens são completamente personalizáveis. $\mathrm{O}$ objetivo do jogo é sobreviver neste mundo futurista e, ao mesmo tempo, buscar uma tecnologia alienígena em um evento denominado "Arkfalls".

O que define a transmidiação de Defiance não se restringe, portanto, a presença multiplataforma dos conteúdos da série, mas sim pela extensão ou conexão do mundo narrativo em outros dispositivos, conforme defende Jenkis (2006). O projeto oferece um mundo virtual que existe em tempo real além do tempo ficcional da série. A participação dos usuários - seja como espectadores ou jogadores - são essenciais para a concretização dessa experiência transmidiática entre os conteúdos televisivos e os lúdicos e interativos do jogo, bem como outras mídias também utilizadas no suporte para a imersão e relacionamento entre os integrantes dessa comunidade, tais como: redes sociais, fóruns, blog, canais de vídeo, site institucional, aplicativos de segunda tela e outros (SYFY, 2015).

O formato MMORPG do game propicia a sensação de imersão ou, segundo McPherson (2002), "vivacidade". Inserem os jogadores em missões com um enredo linear ao mesmo tempo em que permitem a liberdade para explorar, construir, coletar e interagir com os cenários e com os outros jogadores também conectados ao jogo. Esse mesmo espaço e tempo ficcionais podem ser acessados semanalmente através da série televisiva, que, apesar de não acontecer na mesma cidade, fazem parte do mesmo universo. Essa estratégia narrativa garante, de certa forma, a sensação de que os acontecimentos, tanto do programa, quanto do jogo, estejam acontecendo simultaneamente.

Outras iniciativas articuladas pelos produtores reforçam ainda mais essa relação entre mídias. Uma delas aconteceu na primeira temporada, em que uma praga irrompida na trama televisiva era apresentada também como mote para uma série de desafios no game. A solução do jogo reverberava no episódio seguinte da tevê (LAROCCO, 2015). Um cuidado com a sincronização dos mundos é visto também em relação ao eventos metereológicos: quando em determinado momento da série chove, no jogo o mesmo acontece (VAST MEDIA GMBH \& CO KG, 2013). Uma outra ação de extensão trata de uma sequência de códigos exibidos ao longo da terceira temporada que, ao serem inseridos no jogo, destravam um bônus para os jogadores (GLOBOSAT PROGRAMADORA LTDA., 2015).

Os elementos e estratégias de design utilizados nesse projeto, assim como qualquer evento transmídia devem levar em consideração, sobretudo os interesses desses consumidores, de modo a fomentar o envolvimento, participação ou "mobilidade voluntária" (MCPHERSON, 2002) com esse mundo de forma plena. Esses motivadores podem ser encontrados nas construções arquetípicas exploradas nesse universo.

O arquétipo é uma ferramenta indispensável para se compreender o propósito ou a função dos personagens em uma narrativa. Embora existam diversos arquétipos personificados em Defiance, o principal é o arquétipo do Herói, protagonizado por Joshua Nolan. O arquétipo do Herói é o mais trabalhado em narrativas midiáticas ou transmidiáticas porque tem grande efeito para a cultura e para a sociedade (SOUZA, 2012). Enquanto função psíquica é profundamente importante para os indivíduos, pois, a partir dele, cada indivíduo cria e recria uma explicação de mundo e de desempenho de seu papel enquanto herói de sua própria história (RANDAZZO, 1997). Para Vogler (2006), o Herói "representa a busca de identidade e totalidade do ego". Isto é, a narrativa do herói tem como propósito estimular o Herói interior de cada indivíduo.

Vargas (1987) explica que a função do arquétipo do Herói é fundamental para a estruturação da consciência: "sempre que algo de novo e transformador vai se implantando em nossa consciência pessoal e coletiva, algum dinamismo heróico deve ser ativado." (VARGAS, 1987, p. 10). Ou seja, por funcionar como um "modelo reflexo" esse personagem permite que cada pessoa - por projeção - acabe por criar uma narrativa pessoal que ajuda a guiar seu princípio de realidade, sua concepção dos outros e, inconscientemente, diferenciar seu eu e sua identidade. Dessa maneira, cada indivíduo constrói e fornece as diretrizes para a sua vida consciente e emocional espelhando-se nos heróis culturais com os quais se identifica. Assim, o personagem heróico representa para o sujeito uma projeção de quem ser e a qual tribo pertencer, organizando o seu contato com o mundo e suas experiências de vida. Logo, é possível compreender porque esse arquétipo tem poder de fascinar, sendo comumente revivido e atualizado no decorrer da história da humanidade.

Segundo Vogler (2006), na maioria das estruturas da narrativa do Herói, o personagem é apresentado, primeiramente, em seu Mundo Comum, isto é, "como muitas histórias são viagens que levam os heróis e as platéias para Mundos Especiais, a maioria delas começa estabelecendo um Mundo Comum". O Mundo Especial de uma narrativa só é especial se puder ser contrastado a um mundo cotidiano, com as questões de todo dia, das quais o herói é retirado. "O Mundo Comum é o contexto, a base, o passado do herói" (VOGLER, 
2006). Além dessa etapa Joshua passará, em Defiance, por todas as demais descritas por Campbell (1995): recusas, tentações, seduções, entre outras

Sendo assim, o projeto Defiance pode ser considerado uma proposta inovadora no que tange a relação dos indivíduos com a narrativa do Herói. Graças a sua multiplataforma onde o telespectador pode ir além da televisão e dos episódios - é possível embarcar de cabeça na mitologia desse arquétipo, inclusive, vivenciando-o. Ou seja, devido ao jogo, o sujeito torna-se parte da história do Herói de Defiance, tornando-se, muitas vezes, ele próprio.

Se na narrativa das mídias tradicionais já havia grande envolvimento do público por esse arquétipo, os projetos transmidiáticos oferecem maior imersão e mobilização do indivíduo, modificando a forma como ele percebe ou reage a sua própria realidade. No projeto transmidiático o envolvimento pela fantasia é completo, garantindo ainda mais a integração psicológica proporcionada pelo arquétipo do Herói. Isto é, o envolvimento psíquico é mais intenso, pois os espectadores e jogadores introjetam a narrativa do Herói e somam-na a sua própria identidade, confundindo os limites entre o real e virtual, colaborando com sua vida cognitiva e emocional.

A cooparticipação do prossumidor, por meio do jogo, na narrativa da série, corrobora com as estruturas arquetípicas do Herói interior. Assim, o ego tem mais chances de ser integrado as suas partes separadas. Vogler (2006) explica que a narrativa do Herói integra todos os aspectos da personalidade. Para o autor, todos os vilões, mestres, guardiões, demônios, traidores, companheiros, amantes, amigos e inimigos do Herói, podem ser encontrados dentro de cada indivíduo. Assim, a narrativa do Herói tem como tarefa psicológica integrar as partes separadas da identidade em uma entidade completa e equilibrada. "O Ego - isto é - o Herói, que acha que e separado de todas essas partes de si mesmo - deve incorporá-las para se tornar um ser integral" (VOGLER, 2006, p. 52).

\section{Conclusão}

Este artigo demonstrou como a transmídia pode funcionar como meio pelo qual a mitologia participa da construção do mundo, ou seja, retratando aspectos culturais e ideológicos que estão inseridos na coletividade. A transmidiação, por meio de múltiplos canais midiáticos, pode retratar tanto sujeitos, quanto lugares, momentos, situações, experiências ou fatos; sendo que tudo isso está arraigado em uma memória coletiva da qual os sujeitos, de um modo consciente ou inconsciente, cognitivo ou emocional, acabam assumindo um lugar de pertencimento ao que é fantasiado.

Assim, a transmidiação fundamentada em arquétipos permite ao prossumidor projetar-se nos sujeitos que ali estão dispostos; agindo da maneira como eles agem; situando-se naquele lugar e enxergando-se como se fosse aquelas pessoas. Desta forma o uso de arquétipos pode contribuir para um maior engajamento do público com o projeto transmídia, envolvendo-o e convidando-o a participar efetivamente das ações.

\section{References}

CAMPBELL, Joseph. O Herói de Mil Faces. São Paulo, Editora Cultrix/Pensamento, 1995.

CIANCIA, Mariana. Transmedia Design Framework: Un approccio design-oriented alla Transmedia Practice. 2015. 297 f. Tese (Doutorado) - Curso de Dottorato di Ricerca In Design, Dipartimento di Design, Politecnico di Milano, Milão, 2015.

COELHO, Nelly Novaes. O conto de fadas: símbolos, mitos e arquétipos. São Paulo: Paulinas, 1998.

DENA, Christy. (2009). Transmedia Practice: Theorising the Practice of Expressing a Fictional World across Distinct Media and Environments. 2009. 354 f. Tese (Doutorado) Curso de Digital Cultures Program, Department Of Media And Communications, University Of Sydney, Sydney.

FERNANDES, Ermelinda Ganem; FIALHO, Francisco Antonio Pereira. (2014). Tipologias e Arquétipos: a psicologia Profunda como base para uma hermêutica. Florianópolis: Insular.

GIL, Antonio Carlos Gil. (2002). Como elaborar projetos de pesquisa. São Paulo: Atlas.

GIOVAGNOLI, Max. (2011). Transmedia Storytelling: Imagery, Shapes and Techniques. Pittsburgh, Eua: Etc Press.

GLOBOSAT PROGRAMADORA LTDA. (Org.). Série Defiance traz códigos exclusivos para o jogo. (2015). Disponível em: http://syfy.globo.com/programas/defiance/materias/ defiance-game.html.

JENKIS, Henry. Cultura da Convergência. São Paulo: Aleph, 2009. 428 p. Susana Alexandria (trad.).

JOHNSON, Derek. (2009). Franchising Media Worlds: Content Networks and The Collaborative Production of Culture. University of Wisconsin-Madison.

JUNG, Carl Gustav. (2000). A vida simbólica. Petrópolis: Vozes. JUNG, Carl Gustav. (2008a). Os arquétipos e o inconsciente coletivo. Petrópolis: Vozes.

JUNG, Carl Gustav. (2008b). Símbolos da transformação. Petrópolis: Vozes, 2008b.

KELLER, Kevin L.; MACHADO, Marcos. (2007) Gestão Estratégica de Marcas. São Paulo: Pearson Pratice Hall.

LAROCCO, Michael. (2015) Text Commentary Defiance and Transmedia Liveness. Disponível em: <http:// www.criticalcommons.org/Members/mlarocco/ commentaries/1398014551335>.

LUPTON, Elen; PHILLIPS, Jennifer Cole. (2008). Novos fundamentos do design. São Paulo: Cosac Naify.

MARK, Margaret; PEARSON, Carol S. (2001). O Herói e o Fora-da-Lei. Como construir marcas extraordinárias usando o poder dos arquétipos. São Paulo: Cultrix.

MCPHERSON, Tara.(2002). Reload: Liveness, Mobility and the Web. In: MIRZOEFF, Nicholas. The Visual Culture Reader. New York: Routledge, 2002.

MORAES, Fabrício. (2012). Arquétipo e representações arquetípicas. Jung no espírito santo: Por um retorno a C. G. Jung .Disponível em: http://psicologianalitica.com/arqutipoe-representaes-arquetpicas/

NORMAN, Donald A. (2010). The Transmedia Design Challenge: Technology that is Pleasurable and Satisfying. 
Interactions - Tangible Interaction = Form + Computing, Nova York, v. 17, n. 1, p.12-15, fev. 2010. Disponível em: <http:// dl.acm.org/ citation.cfm?id=1649478>.

PETRY, Helen; SILVA. (2011) Roberta Del-Vechio de Oliveira. Os Arquétipos nas Propagandas de Revistas Femininas. Sociedade Brasileira de Estudos Interdisciplinares da Comunicação, 2004. Disponível em: <http://galaxy.intercom. org.br:8180/dspace/bitstream/1904/16885/1/R0461-3.pdf.>

RANDAZZO, Sal. (1997). A criação de mitos na publicidade: como os publicitários usam o poder do mito e do simbolismo para criar marcas. São Paulo: Rocco.

RYAN, Marie-Laurie. (2004). Narrative across Media: The Languages of Storytelling. University of Nebraska Press.

SYFY (Org.). (2015). Defiance. Disponível em: <http://www. syfy.com/defiance>.

SOUZA, Felipe Machado. (2012). Marcas, arquétipos e consumidores: a influência dos produtos e dos anúncios publicitários para a construção da identidade. 2012. 58f. Monografia (Especialização em Psicologia Analítica) Curso de Pós-Graduação em Psicologia Analítica, Pontifícia Universidade Católica do Paraná.
THOMPSON, Kristin. (2007) The Frodo Franchise: The Lord of the Rings and Modern Hollywood. Berkeley: University Of California Press.

TOFFLER, Alvin. (1980). A terceira onda. 18. ed. São Paulo: Record.

VAST MEDIA GMBH \& CO KG (Org.).(2015). Defiance - new case study for SyFy's transmedia project. 2013. Disponível em: <http://vast-media.com/transmedia-project-defiance.

VIEIRA, André Guirland. (2003). Imagem, símbolo e narrativa na psicologia analítica de C. G. Jung. Tese apresentada ao Programa de Pós-Graduação em Psicologia do Desenvolvimento da Universidade do Rio Grande do Sul.

VOGLER, Christopher. (1997). A Jornada do Escritor. Rio de Janeiro, Ampersand Editora.

VON STACKELBERG, Peter. (2011). Creating Transmedia Narratives: The Structure and Design of Stories Told Across Multiple Media. 2011. 332 f. Dissertação (Mestrado) - Curso de Information Design And Technology, Information Design And Technology, Institute Of Technology, New York.

ZOJA, Luigi. (1992). Nascer não basta. São Paulo: Axis Mundi. 